\title{
ACOMPANHAMENTO DE EGRESSOS NO ENSINO SUPERIOR: INSTRUMENTOS, TIPOS, AÇÕES E PROGRAMAS
}

DOI: 10.37702/2175-957X.COBENGE.2021.3621

Gustavo Rossi Martins - gustavorossimartins@gmail.com

Universidade Federal do Espírito Santo

Rua Praia do Ouvidor 15

29192-427 - Aracruz, Espírito Santo - ES

RAMON DE ANGELI CESCONETTO - ramon.cesconetto@edu.ufes.br Universidade Federal do Espírito Santo avenida Antônio Gil Veloso 400 29101-010 - Vila Velha - ES

Rosane Bodart Soares - rosane@ele.ufes.br Universidade Federal do Espírito Santo Rua Goiás 18 29101-580 - Vila Velha - ES

PAULO JOSÉ MELLO MENEGÁZ - paulo.menegaz@ufes.br Universidade Federal do Espírito Santo AVENIDA FERNANDO FERRARI 514 29075-910 - VITÓRIA - ES

Resumo: O SINAES foi instituído como instrumento de avaliação externa das Instituições de Ensino Superior no Brasil, estabelecendo o acompanhamento do aluno egresso como um dos aspectos a ser verificado nas políticas de autoavaliação institucional. Tal acompanhamento representa uma fonte de informação importante para que os gestores destas instituições tracem o perfil dos seus ex-alunos inseridos no mercado de trabalho, os acompanhem e avaliem periodicamente os processos de ensino-aprendizagem dos cursos que ofertam. Este artigo apresenta os mecanismos de captação e avaliação das informações que estão sendo adotadas pelas Instituições de Ensino Superior Brasileiras sobre seus egressos e as ações que estão sendo realizadas a partir dos dados coletados. As informações foram obtidas a partir de consultas aos sítios eletrônicos de 119 instituições de ensino públicas brasileiras. Em particular, analisa como a UFES tem estabelecido sua interação com os ex-alunos e a compara com as práticas 
adotadas por outras Instituições de Ensino Superior. A partir da análise da diversidade de instrumentos encontrados, tanto na sua forma, como na temática abordada bem como das ações produzidas, este trabalho selecionou aquelas práticas consideradas bem-sucedidas no âmbito dos programas de acompanhamento de egressos. Elas são tomadas como exemplos que podem ser seguidos ou avaliados e adaptados às realidades particulares de cada Instituição de Ensino Superior brasileira em sua política de autoavaliação.

Palavras-chave: Autoavaliação institucional. Acompanhamento de egressos. Instrumentos de monitoramento. 


\section{ACOMPANHAMENTO DE EGRESSOS NO ENSINO SUPERIOR: INSTRUMENTOS, TIPOS, AÇÕES E PROGRAMAS}

\section{INTRODUÇÃO}

A criação do Sistema Nacional de Avaliação da Educação Superior - SINAES, ocorrida em 2004 (BRASIL, 2004) e a publicação da Portaria 300 do Ministério de Educação, de 30/01/2006 (BRASIL, 2006), instituíram este como instrumento de avaliação externa das Instituições de Ensino Superior (IES) no Brasil, estabelecendo o acompanhamento do egresso como um dos aspectos a ser verificado nas políticas de autoavaliação institucional. Mesmo assim, quinze anos após a publicação da Portaria Normativa, ainda se percebe que há muito o que fazer por parte das instituições de ensino quanto a esse assunto. Ao revisar este tema, pôde-se perceber que o cenário apontado por Andriola (2014) e Heringer et. al. (2018) ainda não foi alterado, com a publicação de poucos estudos visando o acompanhamento de egressos de cursos de graduação realizados pelas IES brasileiras.

No entanto, o acompanhamento de egressos representa uma fonte de informação importante para que os gestores possam traçar o perfil dos seus ex-alunos inseridos no mercado de trabalho, acompanhar a realidade do mercado de trabalho e avaliar periodicamente o desenvolvimento dos processos de ensino-aprendizagem dos cursos que ofertam (WATANABE e SILVA, 2015; COELHO e DE OLIVEIRA, 2012).

Compreende-se que a busca pela qualidade das IES deve ser posta em prática mediante procedimentos regulares e sistemáticos de avaliação, com fins de encontrar os problemas e discutir soluções para garantir o aprimoramento contínuo (LIMA e ANDRIOLA, 2018). Sendo assim, para se manterem atualizadas, é fundamental que as IES tomem iniciativas de interpelar seus egressos, definam suas políticas de acompanhamento, sistematizem formas de coleta de informação e saibam explorá-las de forma a se beneficiarem e produzirem retornos efetivos para a sociedade (QUEIROZ e DE PAULA, 2016; FERREIRA e PIRES, 2010; DIAS E NUNES, 2017).

Este trabalho visa pesquisar os mecanismos de captação e avaliação de informações que estão sendo adotados pelas IES públicas brasileiras. Em particular, visa analisar como a Universidade Federal do Espírito Santo (UFES) tem estabelecido sua interação com os egressos e comparar com as práticas adotadas por outras IES.

\section{AS ESTRATÉGIAS DE ACOMPANHAMENTO DE ALUNOS EGRESSOS}

Neste trabalho, foram analisados dados obtidos a partir da consulta aos sítios eletrônicos de 119 instituições de ensino públicas brasileiras. A Tabela 1 mostra como as instituições analisadas estão distribuídas pelas cinco regiões do Brasil.

A seguir, serão apresentados os principais aspectos analisados nesta pesquisa. 
Tabela 1 - IES pesquisadas por região.

\begin{tabular}{c|c}
\hline Região & Número de IES \\
\hline Norte & $7,56 \%$ \\
\hline Nordeste & $22,69 \%$ \\
\hline Centro-Oeste e DF & $9,24 \%$ \\
\hline Sudeste & $36,98 \%$ \\
\hline Sul & $23,53 \%$ \\
\hline
\end{tabular}

Fonte: Próprio autor.

\subsection{Instrumento de acompanhamento}

O primeiro aspecto analisado se refere à existência de ferramentas de acompanhamento de egressos nas instituições pesquisadas e, se faz parte de um programa institucional. Observa-se na Figura 1 que cerca de $61,76 \%$ das instituições federais possuem algum instrumento de acompanhamento de alunos egressos e $45,24 \%$ das instituições estaduais também o fazem. Os gráficos também mostram que, mesmo 15 anos após a publicação da Portaria Ministerial No. 300, quase metade das IES públicas ainda não apresentam nenhum tipo de instrumento de acompanhamento de egressos. Além disso, pode-se perceber que os programas existentes são majoritariamente institucionais.

Figura 1 - Existência e tipo de instrumento de acompanhamento.
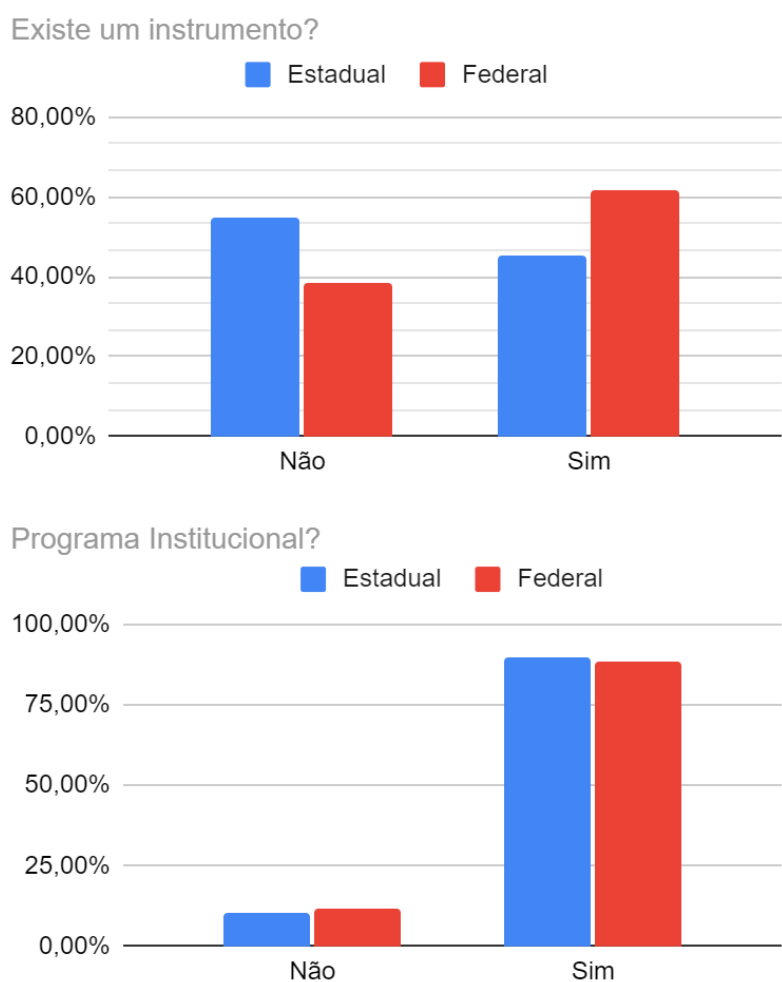

Fonte: Próprio autor.

Outra característica importante é o ano de criação do programa de acompanhamento dos alunos egressos. A Figura 2 mostra que, antes da criação do SINAES em 2004, poucas instituições tinham algum instrumento de avaliação, cerca de 8\%. Após se tornar um requisito obrigatório na avaliação das universidades, essa situação mudou pouco na década seguinte, com a adesão de $26,23 \%$ do total. Somente nos últimos anos houve um 
aumento significativo do número de IES com algum acompanhamento, como pode ser observado no intervalo de 2015 a 2020.

Figura 2 - Ano de criação dos programas de acompanhamento.

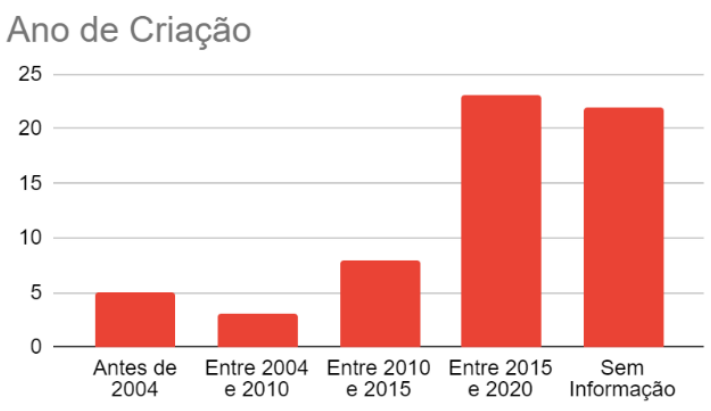

Fonte: Próprio autor.

\section{$2.2 \quad$ Tipo de instrumento}

Os instrumentos de acompanhamento utilizados pelas IES analisadas variam e correspondem a quatro tipos:

1. Formulário aberto;

2. Portal online;

3. Questionário manual;

4. Questionário por e-mail.

O formulário aberto normalmente é obtido por meio de um link público que qualquer pessoa pode preencher, com acesso direto a um questionário. $O$ portal online pode ser específico para os egressos ou ainda uma extensão do portal do aluno. De qualquer modo, o acesso é condicionado por uma identificação (CPF, cadastro, login no portal do aluno etc.), garantindo que pessoas externas não tenham acesso ao questionário. O questionário manual é respondido presencialmente pelo aluno. O questionário por e-mail, por sua vez, é disponibilizado para o aluno através de um link de acesso enviado diretamente para seu e-mail cadastrado. Este pode também ser usado como uma extensão do Portal Online, como meio de ampliar o número de egressos atingidos, ou ao Formulário Aberto.

Nota-se na Figura 3 que os tipos de acompanhamento Portal Online e Formulário Aberto se destacam entre os demais, com respectivamente 57,4\% e 19,7\%. É importante observar que, apesar do Formulário Aberto não garantir a procedência das informações, já que não há nenhum tipo de identificação por parte de quem o preenche, ele é bastante empregado pelas IES, (quase $20 \%$ ). Outro fato notado é que os instrumentos utilizados são majoritariamente eletrônicos, como já era esperado.

Figura 3 - Tipo de instrumento empregado.

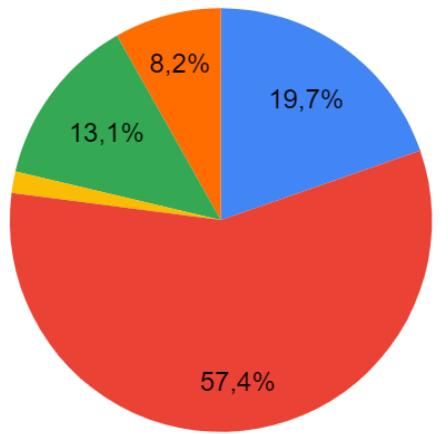

Fonte: Próprio autor
Formulário Aberto

Portal Online

Questionário Manual

Questionário por e-mail

Sem Informação 


\subsection{Obrigatoriedade da participação}

Em sua grande maioria os instrumentos de acompanhamento não são mandatórios aos alunos e necessitam de algum incentivo à sua participação. Cerca de $78,95 \%$ das IES estaduais e $90,48 \%$ das federais, não condicionam a participação do aluno egresso na pesquisa como requisito para sua formação. Nesses casos considera-se que a existência de algum tipo de incentivo para a participação dos egressos poderia elevar o número de participantes.

Figura 4: Obrigatoriedade da participação.

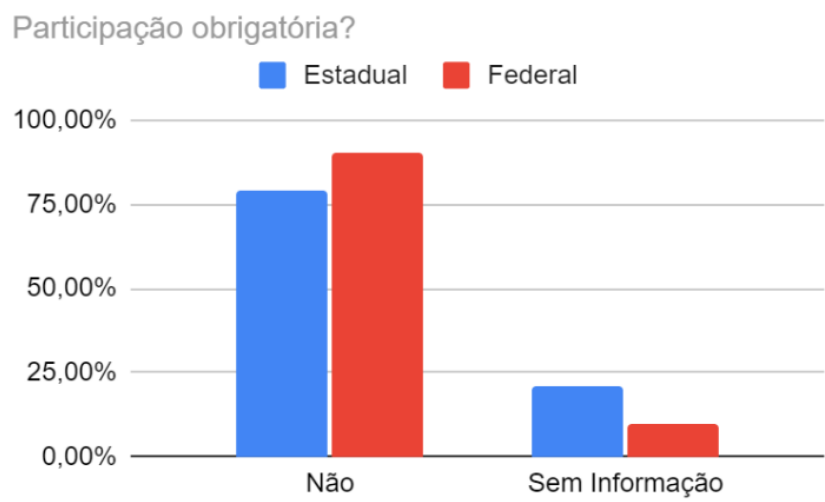

Fonte: Próprio autor.

\subsection{Análise do questionário}

Dentre as IES pesquisadas, somente $54,1 \%$ permitem acessar, direta ou indiretamente, o conteúdo do questionário utilizado no seu instrumento de acompanhamento de egressos, conforme mostrado na Figura 5. Portanto, os dados apresentados a seguir foram obtidos através de formulários abertos ou da análise dos relatórios anuais encontrados nos sítios eletrônicos destas instituições.

Figura 5 - Disponibilidade de acesso ao questionário.

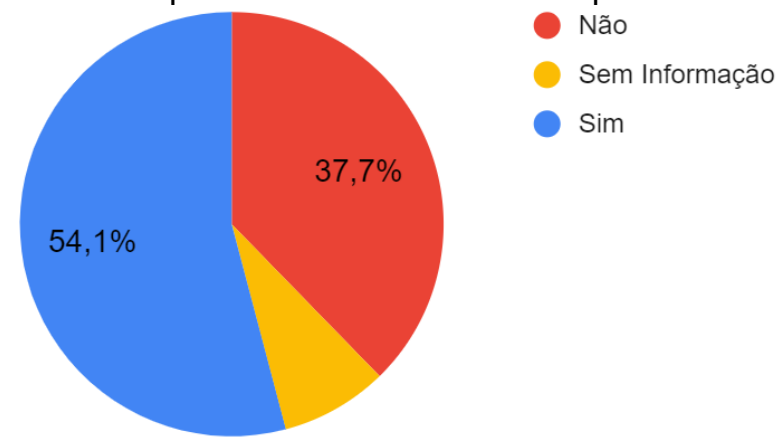

Fonte: Próprio autor.

Analisando os temas presentes nos instrumentos de acompanhamento das instituições pesquisadas, foi possível classificá-los em sete eixos principais:

- Análise do curso de graduação;

- Emprego atual: informações básicas e satisfação;

- Emprego atual: o que o ajudou seu alcance;

- Emprego atual: o que o dificultou seu alcance;

- Papel da língua estrangeira nas atividades de trabalho;

- Capacitações após a graduação;

- Disposição do egresso em ajudar a IES: parcerias/financiamento. 
A Figura 6 mostra a presença de cada eixo nos questionários das IES analisadas. É importante observar que o eixo das ordenadas apresenta o percentual de IES que tem a referida temática em seu instrumento, ao passo que os números indicados nas faixas azuis são números absolutos, ou seja, a quantidade de IES.

Figura 6 - Temáticas dos instrumentos de acompanhamento.

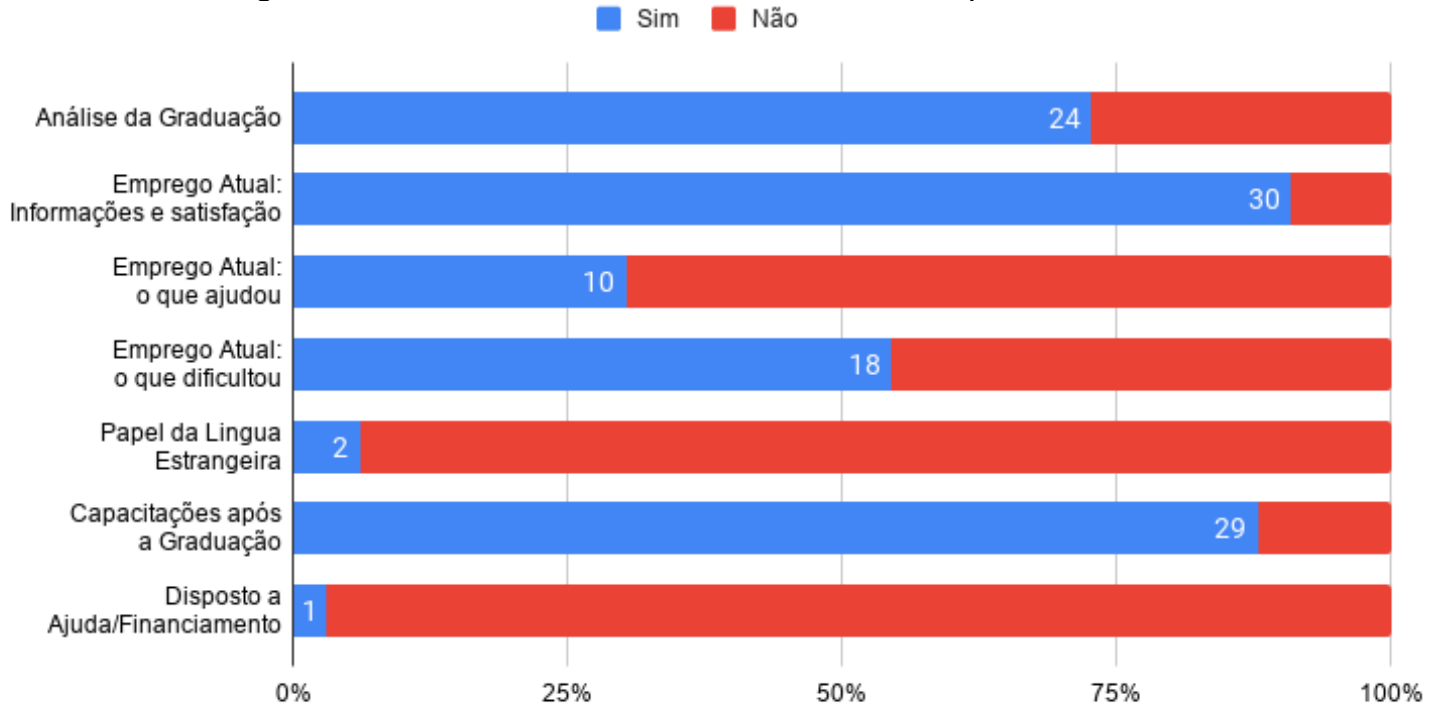

Fonte: Próprio autor.

\subsection{Ações para incentivar a participação do egresso}

Durante o estudo, foi possível observar que algumas instituições executam ações de incentivo à participação de seus egressos em seus programas de acompanhamento. A Figura 7 apresenta uma nuvem de palavras com as ações encontradas durante a pesquisa para este fim.

Figura 7 - Ações visando a maior participação dos egressos nos programas de acompanhamento das IES.
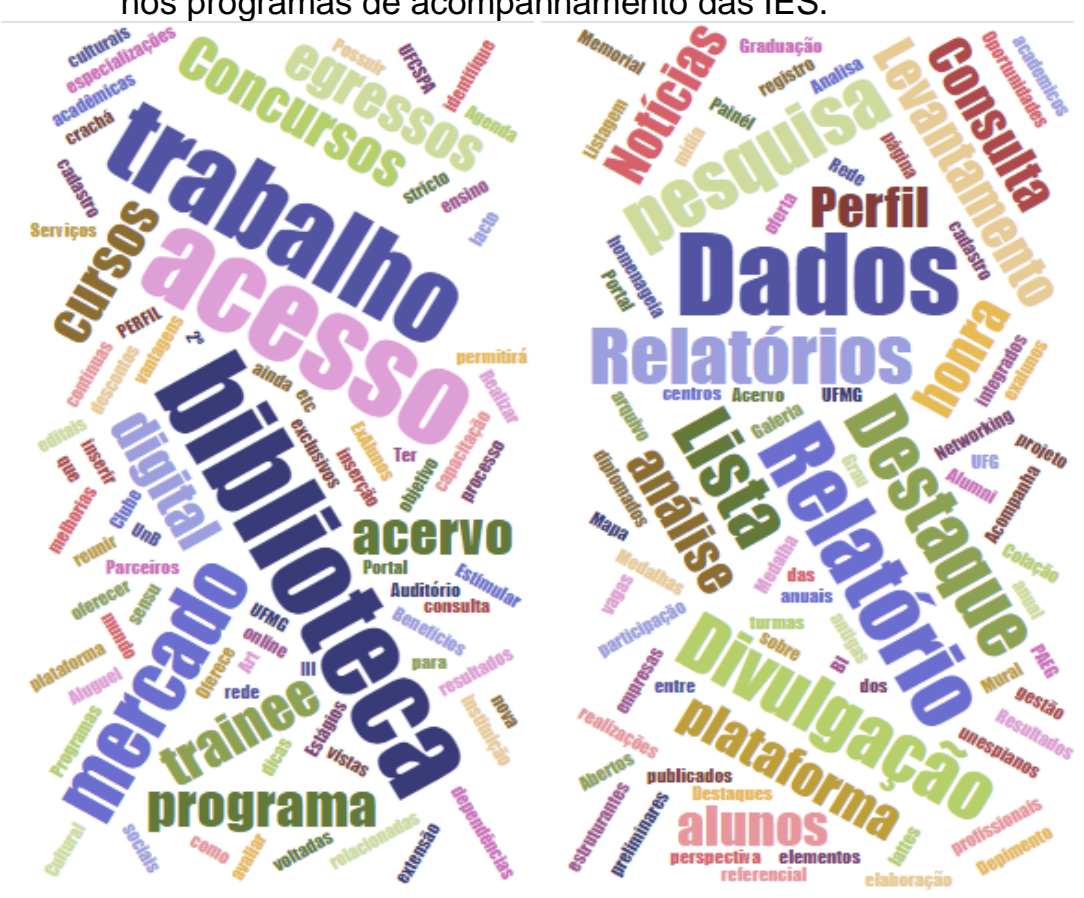

Fonte: Próprio autor. 

especial:

Dentre as diversas ações desenvolvidas pelas IES, dois tipos merecem uma atenção

1 - Medidas que buscam uma maior atratividade do público-alvo:

- Divulgação de oportunidades de emprego no mercado local de trabalho;

- Divulgação de cursos de qualificação ofertados pela IES;

- Acesso ao acervo da biblioteca para o egresso.

2 - Medidas que buscam melhorar a divulgação das ações da IES:

- Divulgação dos dados e relatórios anuais de acompanhamento;

- Divulgação de notícias que mostrem os egressos da IES que são destaque na mídia local por causa de suas atividades ou trabalhos.

\section{$3 \quad$ PROGRAMA DE EGRESSOS DA UFES}

A UFES iniciou seu Programa de Acompanhamento de Estudante Egresso (PAEEg) em 2013 com o objetivo de promover uma melhoria contínua da qualidade dos Cursos de graduação e integrar o processo de Autoavaliação Institucional (AAI). O PAEEg visa criar um canal de comunicação com o egresso e entra em contato com o mesmo via e-mail, solicitando sua participação no Programa. Para isto, basta que o ex-aluno responda à enquete enviada por e-mail.

Ao manter contato com os ex-alunos, a UFES tem a possibilidade de divulgar oportunidades de emprego, programa de trainee, pós-graduação, entre outros eventos de interesse para o processo de formação continuada dos ex-alunos. O Portal de Egressos da UFES disponibiliza os dados dos instrumentos por ela utilizados nos últimos anos de duas formas: um relatório anual da pesquisa para o ano de 2019 e os resultados das enquetes realizadas entre os anos de 2010 e 2016.

Ao analisar esses dois formatos, é possível perceber que, no início (2010 a 2016), o instrumento utilizado era mais detalhado e trazia resultados de maior impacto na proposição de políticas que visassem o aperfeiçoamento do processo de formação e de adequação do graduando às necessidades do mercado atual. No entanto, no ano de 2019, o instrumento sofre uma forte simplificação, se limitando a perguntas sobre o perfil do egresso e sobre sua atual inserção ou não no mercado de trabalho.

A temática das perguntas dos primeiros questionários (2010 a 2014) pode ser definida em cima de 9 eixos:

1. Emprego atual: atuação na área de formação;

2. Emprego atual: tempo decorrente até o início da atuação profissional;

3. Emprego atual: tipo de instituição;

4. Renda salarial;

5. Realização profissional;

6. Análise da graduação: avaliação do curso;

7. Análise da graduação: contribuição do curso para o desenvolvimento cultural e social;

8. Indicaria o curso?

9. Interesse em ministrar palestras para os alunos do curso;

Nas pesquisas de 2015 e 2016, a temática do questionário foi ampliada, passando a abranger mais 4 eixos:

1. Obstáculos à entrada no mercado de trabalho:
- Especialização;
- Exigência de Experiência;
- Falta de Vagas; 
- Falta de Conhecimento Técnico;

- Língua estrangeira.

2. Análise da graduação: conteúdo em comparação com as necessidades do mercado;

3. Educação continuada: fez algum tipo de capacitação?

- Especialização;

- Mestrado;

- Doutorado;

- Pós-doutorado.

4. Mantém contato com a UFES desde a colação de grau?

É importante assinalar que os eixos do questionário utilizado pela UFES no início de seu programa de acompanhamento, estavam alinhados com as temáticas abordadas pelas outras IES, apresentadas na Figura 6. Entretanto, o instrumento utilizado pela UFES não abordava de forma específica o papel da língua estrangeira nem no andamento do curso, nem no desenvolvimento das atividades de trabalho, como acontece em instrumentos utilizados por outras IES. Além disso, ele limitava a contribuição do egresso na melhoria do processo de aprendizado dos alunos do curso apenas como palestrante em algum evento dentro da vida acadêmica, descartando outras formas de atuação e de financiamento adotadas por algumas IES.

No caso da temática sobre o papel da língua estrangeira, pôde-se observar que apenas 1,01\% dos egressos em 2015 e 0,84 \% em 2016 apontaram este como sendo um obstáculo para sua entrada no mercado de trabalho. Talvez, por este motivo, a abordagem da temática tenha sido tão simples nas últimas pesquisas.

Já o instrumento utilizado em 2019, por sua vez, se limita a três temas:

1. Sexo do egresso;

2. Educação continuada: fez algum tipo de capacitação?
- Especialização;
Mestrado;
Doutorado;
- Pós-doutorado;

3. Emprego atual: atuação na área de formação.

Como se pode perceber, houve um grande empobrecimento no instrumento de acompanhamento utilizado pela Ufes. A IES foi questionada sobre as razões que motivaram tal fato, porém, até o momento os autores não receberam uma resposta da instituição.

\section{$4 \quad$ ALGUNS EXEMPLOS QUE SE DESTACAM}

Sendo parte obrigatória da avaliação institucional, como exige o SINAES, é de se esperar que as instituições de ensino desenvolvam suas próprias metodologias de acompanhamento de egressos de maneira efetiva, de modo a contribuir com a melhoria da qualidade dos seus cursos. Entretanto, ainda hoje, quase metade das IES públicas ainda não apresentam nenhum tipo de instrumento de acompanhamento de egressos, conforme apresentado anteriormente. Além disso, foi possível observar que em várias IES, o número de egressos participantes das pesquisas ainda é pequeno, uma vez que não há nem obrigatoriedade de participação, nem algum tipo de ação que incentive a participação dos egressos.

Desta forma, é importante destacar alguns instrumentos e ações que podem ser considerados bem-sucedidos no alcance dos objetivos de um Programa de Acompanhamento de Egressos. Estes podem ser tomados como exemplos e modelos a 
serem utilizados por outras instituições, após devida avaliação e adaptações às realidades particulares de cada IES.

Considerando a diversidade de instrumentos adotado por cada IES, acredita-se que um instrumento de acompanhamento que leve a resultados mais próximos dos objetivos aos quais se dispõe a alcançar, tenha as seguintes características:

- Tenha uma plataforma de acesso própria e restrita, garantindo que a fonte das informações seja exclusivamente os egressos da IES. Desta forma, se aumenta a confiabilidade do instrumento utilizado;

- Tenham um portal ou página eletrônica de acesso aberto, garantindo uma maior transparência ao instrumento, uma vez que as informações e serviços gerados pelo programa de acompanhamento ficam disponíveis para toda a sociedade;

- A temática dos questionários seja focada e objetiva, evitando enquetes muito longas que poderiam desmotivar a participação dos egressos;

- As enquetes com os egressos sejam feitas de forma regular e os resultados sejam disponibilizados de forma organizada e clara no portal ou página do programa de acompanhamento;

- Promova ações que visem incentivar a participação dos egressos nas enquetes e fidelizem seus laços com a IES, para que não percam o contato com a instituição e continuem fazendo parte de suas ações e serviços à comunidade em geral. Dentre algumas ações nesse sentido, podem ser citadas:

- Acesso ao acervo da biblioteca para os egressos;

- Divulgação de oportunidades de emprego e cursos de educação continuada no portal ou página do programa;

- Realização de parcerias a fim de oferecer descontos ou outras vantagens na compra de livros, ingressos ou outros produtos/serviços no portal ou página do programa;

- Realização de parcerias com os próprios egressos para que anunciem seu produto/serviço para a comunidade no portal ou página do programa;

- Divulgação de notícias sobre conteúdos diversos tanto sobre o mundo acadêmico, quanto o mundo do trabalho.

Algumas IES analisadas se destacam no cenário estudado por possuírem algumas ou várias dessas características. A seguir, alguns desses exemplos são mostrados.

\subsection{Alumni USP}

A Alumni USP é uma plataforma que se apresenta com o objetivo de formar uma rede para reunir os egressos desta universidade. Nela, o egresso realiza seu cadastro e passa a contar com todas as ações de fidelização e incentivo descritas anteriormente. $O$ egresso é incentivado a continuar se sentindo como parte da instituição e contribuir para com a sua melhoria. Os indicadores analisados a partir das enquetes respondidas pelos egressos são disponibilizados na própria plataforma através de gráficos, limitando a divulgação de alguns dados considerados restritos. Ainda, seu programa de parcerias permite que empresas ofereçam vagas para cursos e descontos em produtos através da plataforma.

\subsection{Portal AD-UNIFEI}

A Associação dos Diplomados da Universidade Federal de Itajubá mantém um portal para os egressos onde são disponibilizadas notícias e vagas para o mercado de trabalho. 
Neste mesmo portal também são oferecidos produtos, livros e ingressos para o jantar anual de aniversário da instituição. A AD-UNIFEI também oferece ao egresso a oportunidade de se tornar um sócio contribuinte, através do pagamento de uma anuidade. Como sócio contribuinte, o egresso passa a contar com vantagens como sorteios de prêmios e descontos em estabelecimentos de redes hoteleiras e de abastecimento de combustíveis.

\subsection{Alumni UnB}

A Alumni UnB é a associação de egressos da Universidade de Brasília, na qual o exaluno ingressa a partir do preenchimento de um cadastro e do pagamento de um valor mensal. Como benefícios, seus sócios contribuintes contam com descontos em cursos de idiomas, farmácias, restaurantes, academias, entre outros. Além disso, eles têm acesso ao acervo da biblioteca e podem alugar o auditório da associação para a realização de encontros e outros eventos.

\subsection{Egressos.UFC}

O portal dos egressos da Universidade Federal do Ceará, assim como os já citados, também divulga oportunidades de trabalho e de educação continuada nos programas de pós-graduação da instituição. No entanto, ele se destaca dos outros ao possuir um espaço reservado para divulgação de notícias sobre seus egressos, novos projetos e as conquistas alcançadas por eles; acompanhando, dessa forma, as realizações de suas vidas profissionais de perto. Também podem ser encontrados, no portal, o depoimento de diversos egressos sobre o papel e a importância da instituição em suas vidas.

Outro aspecto que chama a atenção, é o formato arrojado e atrativo como as informações obtidas a partir das enquetes com os alunos são disponibilizadas, cativando a atenção de quem acessa o portal. A Figura 8 mostra um desses gráficos, o qual utiliza a plataforma gráfica Microsoft Power BI.

Figura 8 - Exemplo de gráfico de resultados do Portal Egressos da UFC.

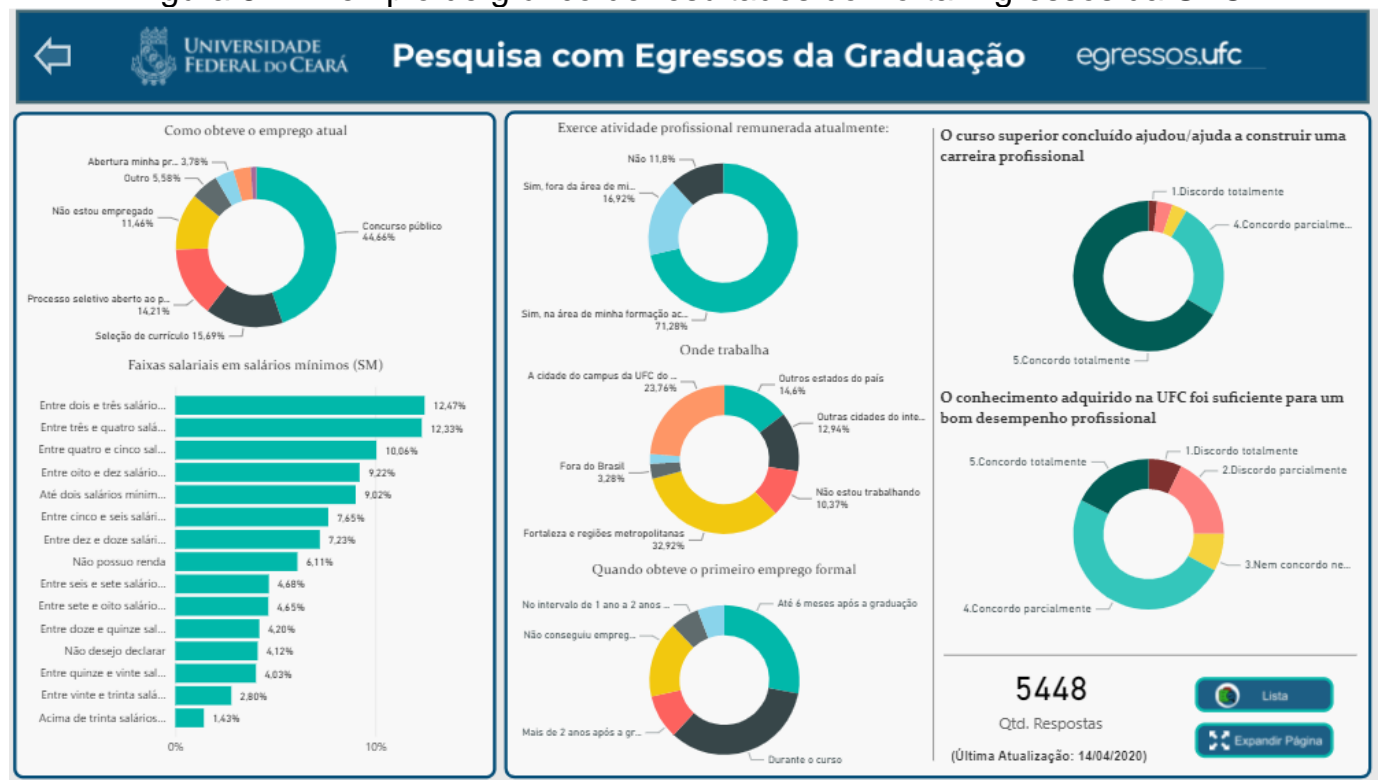

Fonte: https://egressos.ufc.br/nossos-egressos/

\subsection{Analisa UFG}

A Plataforma de Análise de Dados da Universidade Federal de Goiás também é um exemplo no qual as informações a respeito de seus egressos são dispostas de maneira gráfica e clara usando a ferramenta Power BI. Formando o chamado painel de indicadores, 
com indicativos dos egressos considerando curso, sexo, grau acadêmico e série histórica do número de formados, o portal é constantemente atualizado, possibilitando sua visualização através de painéis, para os quais o acesso é público, e através da geração de relatórios somente para pessoas autorizadas, ou seja, com acesso privado.

\subsection{Alumni Unesp}

O Portal Alumni Unesp também é um exemplo que se destaca neste cenário. Além de oferecer informação, oportunidades e benefícios aos egressos, como os exemplos apresentados anteriormente, ele inova ao apresentar um canal para doações que não se restringe aos egressos da instituição através do Programa Parceiro Unesp.

Esse programa tem como objetivo regulamentar o recebimento de apoio de pessoas físicas (alunos, egressos, docentes ou técnico-administrativos) ou jurídicas, tanto na forma de doação de recursos financeiros, bens móveis ou imóveis, bem como na execução direta de serviços ou construção ou reforma de prédios, salas ou laboratórios da universidade. Em contrapartida, a instituição pode autorizar a divulgação do nome e logotipo do Parceiro no próprio site ou em outros canais de comunicação da instituição. Além disso, também é possível a colocação de uma placa de agradecimento com nome e logotipo do Parceiro em local pré-definido.

\section{$5 \quad$ ANÁLISE E NOVAS PROPOSTAS PARA O INSTRUMENTO DE ACOMPANHAMENTO DA UFES}

Diante do cenário exposto, pode-se concluir que, tanto o Portal, quanto o Programa de Acompanhamento de Egressos da UFES podem ser aperfeiçoados.

Um ponto simples e que necessita de mudança a curto prazo é o tipo e o conteúdo da enquete que é disponibilizada para seus egressos. Acredita-se que, para garantir a confiabilidade da informação, a instituição deva realizar seu questionário através de uma plataforma própria, de acesso restrito aos egressos. Pode-se pensar que esse fator seja de difícil execução, mas a instituição já conta com diversos portais desse tipo (Portal do aluno, Portal do professor, Portal do servidor, Lepisma etc.), criados e mantidos pela Superintendência de Tecnologia da Informação (STI) da própria instituição, cujo acesso é feito a partir de senha única. Assim sendo, a criação de um Portal do Egresso não deve ser vista como um obstáculo intransponível. É importante lembrar que hoje a enquete é feita com os egressos através de um Formulário Google, ao qual qualquer pessoa tem acesso.

Além disso, a periodicidade de realização e divulgação das enquetes deve ser regularizada. Como foi exposto anteriormente, o Portal de Egressos da UFES, hoje, disponibiliza o acesso apenas aos resultados dos anos de 2010 a 2016 e 2019.

Outro fato agravante é a falta de ações de estímulo e fidelização da participação do egresso neste processo. Neste caso, a instituição poderia pensar em adotar alguma das ações apresentadas como ações de sucesso realizadas por outras IES.

Outra ação que poderia ser mais bem trabalhada no portal de egressos é a divulgação de oportunidades, notícias, depoimentos e ações realizadas por seus egressos. Isso daria maior visibilidade ao seu programa de acompanhamento, podendo impactar positivamente no nível de participação de egressos. A universidade conta com diversos egressos que vêm sendo homenageados e citados na mídia local e nacional, por seus trabalhos, como é o exemplo do cofundador do PicPay, Dárcio Stehling; do quadrinista Juliano Enrico e do Prof. Anselmo Frizera Neto nas ações que vem desenvolvendo junto ao governo do estado em auxílio no combate à pandemia de Covid-19. 
Por fim, apesar de ser um assunto ainda polêmico no âmbito das IES públicas, poderse-ia pensar na criação de algum tipo de programa de parceria com os egressos como no caso UNIFEI e da Unesp.

\section{CONCLUSÃO}

Observa-se que o cenário nacional das instituições de ensino superior ainda é incipiente no acompanhamento de egressos, com cerca de $44,55 \%$ não possuindo qualquer tipo de acompanhamento, mesmo tendo tido um aumento expressivo nesse número na última década, com várias instituições criando seus programas, pelo menos oficialmente. Os instrumentos de acompanhamento seguem um perfil bastante similar, com o auxílio da internet em todo ou parte do processo de acompanhamento, e as enquetes sendo elaboradas em torno da avaliação do ensino, impacto profissional e capacitações após a graduação.

Os diferenciais estão, principalmente, na abordagem com o aluno, o contato com ele, e os incentivos e ações feitas com os dados coletados. Quanto a isso, destacam-se a transparência com os dados e sua disponibilização, sempre atualizada, por meio de relatórios e ferramentas gráficas como Power BI. A existência de um programa de parcerias pode ser muito positiva para as universidades na execução de projetos e pesquisas, formando uma comunidade sempre crescente com seus ex-alunos, que podem atuar ativamente para isso. E ainda, a divulgação de notícias referentes aos egressos pode contribuir ainda mais nesse senso de comunidade e parceria, valorizando o papel da instituição na sociedade de modo geral.

A UFES falha em realizar essas últimas contribuições, possuindo uma plataforma de acompanhamento ainda muito simples e, por isso, com muito espaço para melhorias. Como seu programa é recente, de 2013, e já recebeu melhorias no emprego dos questionários, espera-se que siga efetuando mudanças em todo o programa de maneira a não somente cumprir com a exigência mínima do SINAES, mas também promover melhorias no ensino e na própria universidade.

\section{REFERÊNCIAS}

ANDRIOLA, W. B. Estudo de egressos de cursos de graduação: subsídios para a autoavaliação e o planejamento institucionais. Educar em revista, Curitiba, n. 54, p. 203220, 2014.

BRASIL. Portaria no. 300 de 30 de janeiro de 2006. Diário Oficial [da] República Federativa do Brasil, Poder Executivo, Brasília, DF, 30 jan. 2006. Seção 1, p. 5.

BRASIL. Lei no. 10.861 de 14 de abril de 2004. Diário Oficial [da] República Federativa do Brasil, Poder Executivo, Brasília, DF, 14 abr. 2004. Seção 1, p. 3.

COELHO, M. S. C.; DE OLIVEIRA, N. C. M. Os Egressos no processo de avaliação.

Revista e-Curriculum, São Paulo, v. 9, n. 2, p. 1-19, ago. 2012.

ETZKOWITZ, H. Reconstrução criativa: hélice tripla e inovação regional. Revista Inteligência Empresarial, Rio de Janeiro: Editora e-papers, n. 23, p. 2-13, 2005. 
FERREIRA, A. D.; PIRES, O. H. Egressos da UTP: percepções e relacionamento. 2010. $52 \mathrm{f}$. Trabalho de Conclusão de Curso (Graduação) - Faculdade de Ciências Sociais Aplicadas, Universidade Tuiuti do Paraná, Curitiba, 2010.

HERINGER, A. A. F.; RIBEIRO, D. J.; GRASSI, L. B.; ASTORE, L. M.; CUNHA, C. C. M.; MENEGÁZ, P. J. M.; SOARES, R. B. Acompanhamento de Egressos: um cenário sobre a existência e os instrumentos utilizados pelas IES públicas brasileiras. In: XLVI

CONGRESSO BRASILEIRO DE EDUCAÇÃO EM ENGENHARIA, Salvador, 2018. Anais. Salvador: Universidade Federal da Bahia, 2018.

LIMA, L. A.; ANDRIOLA, W. B. Acompanhamento de egressos: subsídios para a avaliação de Instituições de Ensino Superior (IES). Avaliação: Revista da Avaliação da Educação Superior, Campinas, v. 23, n. 1, p. 104-125, 2018.

QUEIROZ, T. P.; DE PAULA, C. P. A. Dimensões do relacionamento entre a universidade e seus egressos por meio da informação: o caso da Universidade Federal de Minas Gerais. Em Questão, Belo Horizonte, v. 22, n. 1, p. 37-66, jan./abr. 2016.

WATANABE, M.; SILVA, M. A. Aproximação da academia-indústria-governo: uma construção para dinamizar a inovação. In: XII Seminário Internacional Demandas Sociais e Políticas Públicas na Sociedade Contemporânea. Anais. Universidade de Santa Cruz do Sul, 2015.

\title{
HIGHER EDUCATION GRADUATES MONITORING: INSTRUMENTS, TYPES, ACTION AND PROGRAMS
}

\begin{abstract}
SINAES was chosen as an instrument for external evaluation of Higher Education Institutions in Brazil, establishing the monitoring of graduates as one of the aspects to be verified in institutional self-evaluation policies. Such monitoring represents an important source of information for the managers of these institutions to outline the profile of their former students in the labor market, to accompany them and to periodically evaluate the teaching-learning processes of the courses they offer. This article presents the mechanisms for capturing and evaluating the information that is being adopted by Brazilian Higher Education Institutions about their graduates and the actions that are being carried out based on the data collected. These informations were obtained by consulting the websites of 119 Brazilian public education institutions. In particular, it analyzes how UFES has established its interactions with graduates and compares it with the practices adopted by other Higher Education Institutions. Based on the analysis of the diversity of instruments found as well as the actions produced, this work selected those practices considered successful in the scope of the programs for monitoring graduates. They are taken as examples that can be followed or evaluated and adapted to the particular realities of each Brazilian Higher Education Institution in its self-assessment policy.
\end{abstract}

Keywords: Institutional self-assessment. Monitoring graduates. Monitoring instruments. 